\title{
Pulmonary Function, Aerobic Capacity and Related Variables in Patients With Ankylosing Spondylitis
}

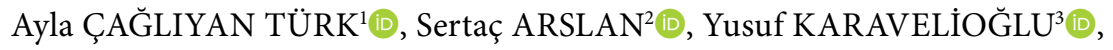

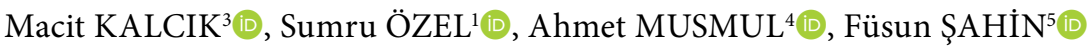 \\ ${ }^{1}$ Department of Physical Medicine and Rehabilitation, Hitit University, Faculty of Medicine, Çorum, Turkey \\ ${ }^{2}$ Department of Chest Diseases, Hitit University, Faculty of Medicine, Çorum, Turkey \\ ${ }^{3}$ Department of Cardiology, Hitit University Faculty of Medicine, Çorum, Turkey \\ ${ }^{4}$ Department of Medical Services and Techniques, Vocational School of Health Services Osmangazi University, Eskişehir, Turkey \\ ${ }^{5}$ Department of Physical Medicine and Rehabilitation, Pamukkale University Faculty of Medicine, Denizli, Turkey
}

\begin{abstract}
Objectives: This study aims to evaluate the cardiopulmonary functions and exercise performance of patients with ankylosing spondylitis (AS) and to investigate the relationship between these parameters and disease activity, spine mobility and quality of life (QoL).

Patients and methods: Forty-five patients with AS (group 1; 33 males, 12 females; mean age $43.1 \pm 12.1$ years; range 22 to 70 years) and 30 control subjects (group 2; 23 males, 7 females; mean age 42.8 \pm 10.0 ; range 23 to 70 years) were included in the study. Disease activity was assessed with the Bath Ankylosing Spondylitis Disease Activity Index and spinal mobility measures with the Bath Ankylosing Spondylitis Metrology Index (BASMI). The Ankylosing Spondylitis Quality of Life (ASQoL) Questionnaire and the Maastricht Ankylosing Spondylitis Enthesitis Score (MASES) were used. The pulmonary function test (PFT) and cardiopulmonary exercise testing (CPET) were performed.

Results: There was no significant difference between groups 1 and 2 in terms of mean age. The peak expiratory flow value in PFT was significantly lower in group $1(p<0.05)$. In group 1, the duration of CPET was significantly shorter, and maximum work load and metabolic equivalent were significantly lower than in group $2(\mathrm{p}<0.001)$. Maximum oxygen uptake $\left(\mathrm{VO}_{2 \mathrm{max}}\right)$ in peak responses, work and heart rate were significantly lower in group 1. The duration of CPET and maximum work were negatively correlated with age and $B A S M I(p<0.001) . \mathrm{VO}_{2 m a x}$ was negatively correlated with age, MASES and ASQoL $(p<0.05)$.
\end{abstract}

Conclusion: There was no significant difference in PFT parameters between the groups. On the other hand, CPET parameters were significantly lower in the AS group. While CPET parameters are affected by spinal mobility, declining aerobic capacity affects QoL.

Keywords: Ankylosing spondylitis, cardiopulmonary exercise testing, pulmonary function test, quality of life.

Ankylosing spondylitis (AS) is a chronic inflammatory rheumatic condition primarily affecting the axial skeleton. It is the main subtype of spondyloarthritis. ${ }^{1}$ Uveitis, osteoporosis, intestinal disease and heart, lung, skin and kidney involvement may be observed in patients with concomitant extra-articular conditions. ${ }^{2}$ Aortic regurgitation, cardiac conduction disorders, heart problems, pulmonary fibrosis of the upper lobes and other lung problems have been described. Spinal motion restriction and deformity, functional impairment, severe handicap and decreased quality of life (QoL) may be observed with disease progression..$^{3,4}$

Received: August 13, 2018 Accepted: November 25, 2018 Published online: April 22, 2019

Correspondence: Yusuf Karavelioğlu, MD. Hitit Üniversitesi Tıp Fakültesi Kardiyoloji Anabilim Dalı, 19040 Çorum, Turkey. Tel: +90 533 - 4314171 e-mail: drcomtr@gmail.com

\section{Citation:}

Çağlıyan Türk A, Arslan S, Karavelioğlu Y, Kalcık M, Özel S, Musmul A, et al. Pulmonary function, aerobic capacity and related variables in patients with ankylosing spondylitis. Arch Rheumatol 2019;34(3):317-325. 
It is reported that cardiovascular and pulmonary risk factors are high in this population. ${ }^{5}$ The severity of cardiac involvement may range from asymptomatic to valve defects, severe heart failure and arrhythmia. ${ }^{5,6}$ Increased cardiac morbidity risk, including coronary artery disease, has been reported in patients with AS. ${ }^{7}$ Decreased aerobic capacity may be found in relation to cardiovascular disease. ${ }^{8}$ Respiratory abnormalities in AS are typically restrictive. ${ }^{9}$ Apical pulmonary fibrosis is also associated with $\mathrm{AS}$, but the prevalence is low. ${ }^{10}$ However, a decrease in chest expansion may also result in a restriction of vital capacity, and aerobic capacity is reduced compared to the general population. ${ }^{9,11,12}$ In addition to pulmonary and cardiac dysfunction, other factors that may contribute to aerobic capacity impairment include decreased physical activity, peripheral arthritis, fatigue and muscle weakness. ${ }^{13}$ However, previous studies of aerobic capacity in patients with AS are limited in number and contradictory. The relative contribution of all these factors (cardiac, pulmonary, musculoskeletal disorders, inflammation, fatigue) to decreased aerobic capacity has not been quantitatively examined. ${ }^{8,10,14}$ Improved knowledge in this area will be clinically important both to understand the pathophysiological basis of exercise restriction and to develop effective training/rehabilitation strategies for patients in this setting. ${ }^{8,10}$

Cardiopulmonary exercise testing (CPET) is a non-invasive procedure that provides diagnostic and prognostic information to assess an individual's capacity during dynamic exercise. CPET-based exercise under controlled metabolic conditions is based on the investigation of the respiratory system, cardiovascular system and cellular response. It allows an integrated assessment not only for pulmonary and cardiovascular systems, but also for the response to exercise, including the musculoskeletal system. ${ }^{15}$

In this study, we aimed to evaluate cardiopulmonary functions and exercise performance of patients with AS and to investigate the relationship between these parameters and disease activity, spine mobility and QoL.

\section{PATIENTS AND METHODS}

This cross-sectional study was conducted at Hitit University, Faculty of Medicine between
June 2016 and July 2017 and included 45 patients with AS (group 1; 33 males, 12 females; mean age $43.4 \pm 12.1$ years; range 22 to 70 years) who met the Modified New York Criteria and 30 age-matched control subjects (group 2; 23 males, 7 females; mean age $42.8 \pm 10.0$; range 23 to 70 years). The control group consisted of patients' relatives who accompanied them to the hospital. The exclusion criteria included concurrent cardiac or respiratory disease, use of beta-blockers, arthritis/enthesopathy or contracture in the lower extremity that prevented exercise on the bike and arthroplasty or major surgery in the knee or hip joints. Patients' age, height, weight, smoking history and past medical history were recorded. Patients' pain levels were assessed as night and day with a $10-\mathrm{cm}$ visual analog scale (VAS). ${ }^{16}$ The study protocol was approved by the Hitit University, Faculty of Medicine Ethics Committee. A written informed consent was obtained from each participant. The study was conducted in accordance with the principles of the Declaration of Helsinki.

Disease activity was evaluated using the Bath Ankylosing Spondylitis Disease Activity Index (BASDAI). ${ }^{17}$ Functional status was assessed with the Bath Ankylosing Spondylitis Functional Index (BASFI). ${ }^{18}$ Mobility measurements were performed with the Bath Ankylosing Spondylitis Metrology Index (BASMI). ${ }^{19}$ The following parameters were evaluated for mobility: cervical rotation, ${ }^{8}$ lumbar lateral flexion, ${ }^{20}$ modified lumbar Schober measurement, occiput-to-wall distance (ODW), ${ }^{20}$ intermalleolar distance ${ }^{20}$ and chest expansion. ${ }^{21}$ QoL was evaluated by the Ankylosing Spondylitis Quality of Life (ASQoL) Questionnaire. ${ }^{22}$ The Maastricht Ankylosing Spondylitis Enthesitis Score (MASES) was used for the assessment of enthesitis. ${ }^{23}$

The erythrocyte sedimentation rate (ESR) and C-reactive protein (CRP, normal range 0-5 mg/L) levels were measured, and complete blood count results were evaluated for the assessment of disease activity.

As part of the pulmonary function test (PFT), spirometry tests were performed by a trained and experienced spirometry technician in accordance with the American Thoracic Society guidelines using the ZAN 100 (nSpire Health Inc., Oberthulba, Germany) spirometry device. ${ }^{24}$ 
Forced vital capacity (FVC), forced expiratory volume in one second $\left(\mathrm{FEV}_{1}\right), \mathrm{FEV}_{1} / \mathrm{FVC}$ and peak expiratory flow (PEF) ratios were examined.

Whether there was any condition preventing patients from participating in CPET was determined according to the guidelines. For this purpose, the medical history, physical examination, resting electrocardiogram (ECG) and laboratory tests of all participants were evaluated by a cardiologist. In all participants without contraindications, maximum fatigue was defined as the target. The respiratory exchange ratio (RER) was aimed to reach a value of 1.1 , and values above 1.05 were also accepted. RER reflects the ratio of carbon dioxide production to oxygen uptake $\left(\mathrm{VCO}_{2} / \mathrm{VO}_{2}\right)$. The gas exchange measurement was conducted through breath-by-breath analysis using the Metalyzer 3B (Metasoft Studio 4.8, CORTEX Biophysik GmbH, Leipzig, Germany) which continuously and simultaneously determines respiratory oxygen uptake $\left(\mathrm{VO}_{2}\right)$, carbon dioxide production $\left(\mathrm{VCO}_{2}\right)$ and ventilatory measures. The instantaneous values were determined by the average of the values of every final 10 seconds. ${ }^{25}$ All exercise tests were performed by a computercontrolled cycle ergometer (Ergoline Bicycle
Ergometer Ergoselect 200, Bitz, Germany) under supervision by an experienced technician and nurse from 10:30 AM to 1:00 PM in an airconditioned laboratory with the temperature set at $18-22^{\circ} \mathrm{C}$. During the test, a continuous recording was performed by a 12-lead ECG (Meta control 3000 connects the CORTEX MetaLyzer). Blood pressure was monitored non-invasively every two minutes by an automated sphygmomanometer with the appropriate cuff size from the right arm before and during the test and periods.

As the test protocol, the ramp protocol on a bicycle ergometer was adopted. Periods of three minutes rest and then three minutes of unloaded cycling, followed by an increase of $10 \mathrm{~W}$ every minute ramp protocol starting at $25 \mathrm{~W}$, were utilized. It was ensured that the pedaling frequency of the participants was over 60 per minute. According to the guidelines, people were encouraged to continue until they could no longer pedal, except in cases where the test had to be terminated. After the test was completed, the resting phase was started at the end of three minutes of unloaded pedaling. Heart rate, blood pressure, $\mathrm{VO}_{2}$, metabolic equivalent (MET), work, oxygen pulse and RER were assessed at peak

Table 1. Comparison of clinical and laboratory parameters of patients with AS and control group

\begin{tabular}{|c|c|c|c|c|c|}
\hline & \multicolumn{2}{|c|}{ Patient group with AS $(n=45)$} & \multicolumn{2}{|c|}{ Control group $(n=30)$} & \multirow[b]{2}{*}{$p$} \\
\hline & $\mathrm{n}$ & Mean \pm SD & $\mathrm{n}$ & Mean \pm SD & \\
\hline Age (year) & & $43.1 \pm 12.1$ & & $42.8 \pm 10.0$ & $0.914^{*}$ \\
\hline Body mass index $\left(\mathrm{kg} / \mathrm{m}^{2}\right)$ & & $27.0 \pm 5.1$ & & $26.3 \pm 4.2$ & $0.514^{*}$ \\
\hline $\begin{array}{l}\text { Smoking } \\
\text { Yes } \\
\text { No }\end{array}$ & $\begin{array}{l}19 \\
26\end{array}$ & & $\begin{array}{l}14 \\
16\end{array}$ & & $0.887^{*}$ \\
\hline Visual analog scale night-time & & $3.4 \pm 3.4$ & & - & \\
\hline Visual analog scale day-time & & $3.6 \pm 3.1$ & & - & \\
\hline Bath Ankylosing Spondylitis Disease Activity Index & & $4.1 \pm 2.1$ & & - & \\
\hline Bath Ankylosing Spondylitis Functional Index & & $3.4 \pm 2.6$ & & - & \\
\hline Bath Ankylosing Spondylitis Metrology Index & & $2.4 \pm 2.0$ & & $0.0 \pm 0.0$ & $<0.001^{* *}$ \\
\hline Chest expansion $(\mathrm{cm})$ & & $4.3 \pm 1.4$ & & $6.5 \pm 0.7$ & $<0.001^{* *}$ \\
\hline Ankylosing Spondylitis Quality of Life & & $9.3 \pm 5.5$ & & - & \\
\hline Sedimentation (mm/hr) & & $41 \pm 18.7$ & & $24 \pm 8.5$ & $<0.001^{* * *}$ \\
\hline C-reactive protein & & $43 \pm 11.1$ & & $28 \pm 4.5$ & $<0.001^{* *}$ \\
\hline
\end{tabular}


Table 2. Comparison of PFT values between control group and patients with AS

\begin{tabular}{|c|c|c|c|}
\hline & Patient group with AS $(n=45)$ & Control group $(n=30)$ & \\
\hline & Mean \pm SD & Mean \pm SD & $p$ \\
\hline Forced vital capacity & $3.4 \pm 0.8$ & $3.7 \pm 0.7$ & $0.131^{*}$ \\
\hline Forced expiratory volume in one second & $3.0 \pm 0.7$ & $3.2 \pm 0.6$ & $0.104^{* *}$ \\
\hline Forced expiratory volume in one second/Forced vital capacity (\%) & $109.0 \pm 6.9$ & $110.5 \pm 5.8$ & $0.248^{* *}$ \\
\hline Peak expiratory flow (/sec) & $5.9 \pm 1.6$ & $6.8 \pm 1.7$ & $0.020^{*}$ \\
\hline
\end{tabular}

cardiovascular response and ventilatory threshold.

\section{Statistical analysis}

All data analyses were performed using the IBM SPSS version 21.0 software (IBM Corp., Armonk, NY, USA). Continuous quantitative variables were expressed as $\mathrm{n}$, mean and standard deviation. Qualitative or score variables were expressed as $\mathrm{n}$, median, $25^{\text {th }}$ and $75^{\text {th }}$ percentiles. Continuous variables consisted of independent measurements and normal distribution was analyzed with independent samples t-test. Data without normal distribution were analyzed with Mann-Whitney $U$ test. Pearson correlation or Spearman correlation tests were used to determine the relationship and direction between the variables according to the normality test results. Chi-square tests were applied to variables in the categorical structure. Probability values of $\mathrm{p}<0.05$ were considered statistically significant.

\section{RESULTS}

The female/male ratio was similar in both groups ( $p>0.05)$. The duration of illness was $13.8 \pm 12.0$ years in group 1 . Age, body mass index, smoking history, VAS, BASDAI, BASFI, BASMI, chest expansion, ASQoL scores, ESR, $\mathrm{CRP}$ values and comparisons of the groups are presented in Table 1. BASMI, ESR and CRP values were significantly higher in group 1 , while chest expansion was significantly lower than in group 2 (Table 1).

In addition, complete blood count results were compared, and it was determined that only the hemoglobin value was significantly lower in group 1 than in group $2(14.3 \pm 1.9$ and $14.8 \pm 1.7$, respectively; $p>0.04)$. A comparison of the PFT values of group 1 with group 2 is presented in Table 2. Only the PEF value in the PFT assessment was significantly lower in group 1 $(p<0.05)$ (Table 2). While a restrictive respiratory pattern was determined in 10 patients in group 1 and an obstructive respiratory pattern in two patients in group 2, a restrictive respiratory pattern was found in only three patients in group 2 ( $\mathrm{p}>0.05)$.

Comparisons of the CPET values of groups 1 and 2 are presented in Table 3 . In group 1 , the duration of CPET was significantly shorter than group 2, while maximum work and maximum MET were significantly lower $(p<0.001)$. $\mathrm{VO}_{2 \max }$ (mL/kg/minute) at peak responses, work and heart rate were significantly lower in group 1 , while there was no difference between the resting state parameters of both groups $(p<0.05)$.

The study for the correlation of the demographic and clinical parameters (age, BASDAI, BASFI, ODW and ASQoL) with PFT and CPET parameters in group 1 is presented in Table 4.

There was a negative correlation between FVC and $\mathrm{FEV}_{1}$ and age, BASMI and ODW ( $\left.<<0.001\right)$. There was a positive correlation between FVC and $\mathrm{FEV}_{1}$ and chest expansion $(\mathrm{p}<0.001)$. The duration of CPET and maximum work had a negative correlation with age and BASMI $(p<0.001)$, and it had a positive correlation with chest expansion $(p<0.001)$. $V_{2} O_{2 m a x}$ (mL $/ \mathrm{kg} /$ minute) was negatively associated with age $(p<0.001)$, MASES $(p<0.001)$ and QoL $(p<0.05)$. Peak $V_{2} \quad\left(V_{2 p e a k}\right)$, work (peak) and heart rate (peak) were again negatively correlated with age and BASMI but positively with chest expansion $(\mathrm{p}<0.05)$. The $\mathrm{VO}_{2 \text { peak was }}$ also associated negatively with BASFI $(p<0.05)$. Peak MET was negatively correlated with age 
Table 3. Comparisons of CPET values between patients with AS and control group

\begin{tabular}{|c|c|c|c|}
\hline & Patient group with AS ( $n=45$ ) & Control group $(n=30)$ & \\
\hline & Mean \pm SD & Mean \pm SD & $p$ \\
\hline Total duration (sec) & $986.2 \pm 194.0$ & $1316.3 \pm 307.3$ & $<0.001^{*}$ \\
\hline Max work (watt) & $116.3 \pm 25.9$ & $154.1 \pm 29.8$ & $<0.001^{*}$ \\
\hline Max metabolic equivalent & $6.3 \pm 1.1$ & & $<0.001^{* *}$ \\
\hline \multicolumn{4}{|l|}{ Resting parameters } \\
\hline HR (beats/min) & $90.6 \pm 14.4$ & $84.7 \pm 13.3$ & $0.078^{*}$ \\
\hline SBP (mmHg) & $135.3 \pm 24.3$ & $132.0 \pm 13.3$ & $0.545^{*}$ \\
\hline DBP (mmHg) & $81.6 \pm 10.4$ & $87.1 \pm 12.1$ & $0.079^{*}$ \\
\hline \multicolumn{4}{|l|}{ Peak response } \\
\hline HR (beats/min) & $165.6 \pm 14.0$ & $172.6 \pm 12.2$ & $0.028^{*}$ \\
\hline SBP (mmHg) & $210.7 \pm 30.4$ & $206.2 \pm 26.8$ & $0.514^{*}$ \\
\hline $\mathrm{DBP}(\mathrm{mmHg})$ & $96.6 \pm 24.1$ & $97.8 \pm 24.8$ & $0.834^{*}$ \\
\hline $\mathrm{VO}_{2 \max }(\mathrm{mL} / \mathrm{kg} / \mathrm{min})$ & $25.7 \pm 5.8$ & $31.2 \pm 4.9$ & $<0.001^{*}$ \\
\hline Metabolic equivalent & $6.3 \pm 1.1$ & & $<0.001^{* *}$ \\
\hline Work (watts) & $121.8 \pm 30.9$ & $148.5 \pm 35.9$ & $<0.001^{*}$ \\
\hline Oxigen pulse (mL/beat) & $12.2 \pm 2.8$ & $13.5 \pm 3.3$ & $0.064^{*}$ \\
\hline Respiratory exchange ratio & $1.1 \pm 0.1$ & $1.1 \pm 0.1$ & $0.952^{* * *}$ \\
\hline \multicolumn{4}{|l|}{ Ventilatory threshold } \\
\hline Heart rate (beats/min) & $115.0 \pm 22.9$ & $116.7 \pm 16.6$ & $0.632^{* *}$ \\
\hline Sistolic blood pressure $(\mathrm{mmHg})$ & $175.2 \pm 30.1$ & $170.4 \pm 22.7$ & $0.487^{*}$ \\
\hline Diastolic blood pressure $(\mathrm{mmHg})$ & $91.3 \pm 25.2$ & $91.1 \pm 18.2$ & $0.715^{* * *}$ \\
\hline Work (watts) & $59.5 \pm 17.9$ & $69.4 \pm 24.1$ & $0.055^{*}$ \\
\hline $\mathrm{VO}_{2 \max } \mathrm{VT} 1(\mathrm{~mL} / \mathrm{kg} / \mathrm{min})$ & $14.3 \pm 2.5$ & $14.8 \pm 3.5$ & $0.807^{* *}$ \\
\hline Oxigen pulse (mL/pulse) & $10.1 \pm 4.6$ & $10.1 \pm 2.7$ & $0.213^{* *}$ \\
\hline Respiratory exchange ratio & $0.9 \pm 0.0$ & $0.9 \pm 0.1$ & $0.822^{*}$ \\
\hline
\end{tabular}

and MASES $(p<0.05)$, while there was no correlation between RER and clinical variables. $\mathrm{VO}_{2}$ was correlated with all clinical values except age and QoL $(p<0.05)$. Although ESR was negatively correlated with maximum load and $\mathrm{FEV}_{1}(\mathrm{p}<0.05)$, there was no correlation of CRP with CPET and PFT parameters.

\section{DISCUSSION}

In our study, pulmonary function tests of patients with AS were similar to those of control subjects. The aerobic capacities of patients with AS were significantly reduced compared to controls, but there was no difference between resting CPET measurements. CPET duration, peak work, and peak MET from the aerobic test parameters were decreased with age and BASMI scores. These parameters were positively correlated with chest expansion.

Several studies investigating the aerobic capacities of patients with AS have indicated conflicting results when compared to healthy individuals. ${ }^{7,10,26} \mathrm{~A}$ study by Elliott et al. ${ }^{26}$ was the first to present that the maximum oxygen uptake $\left(\mathrm{VO}_{2 \text { max }}\right)$ and the estimated $\mathrm{VO}_{2 \max }$ in patients with AS was lower than the measured $\mathrm{VO}_{2 \max }$ of the control group. The study sample consisted 
Table 4. Correlation of demographic and clinical parameters with PFT and CPET parameters in patients with AS

\begin{tabular}{|c|c|c|c|c|c|c|c|}
\hline & Age (year) & BASDAI & BASFI & BASMI & ASQoL & $\mathrm{CE}$ & MASES \\
\hline \multicolumn{8}{|l|}{ FVC } \\
\hline r & -0.517 & -0.086 & -0.299 & -0.643 & -0.212 & 0.732 & -0.297 \\
\hline $\mathrm{p}$ & $0.000^{*}$ & 0.587 & 0.054 & $0.000^{*}$ & 0.179 & $0.000^{*}$ & 0.057 \\
\hline \multicolumn{8}{|c|}{$\mathrm{FEV}_{1}$} \\
\hline $\mathrm{r}$ & -0.543 & -0.104 & -0.282 & -0.622 & -0.194 & 0.712 & -0.296 \\
\hline $\mathrm{p}$ & $0.000^{*}$ & 0.514 & 0.071 & $0.000^{*}$ & 0.219 & $0.000^{*}$ & 0.057 \\
\hline \multicolumn{8}{|c|}{ CPET duration } \\
\hline r & -0.433 & -0.111 & -0.286 & -0.364 & -0.239 & 0.496 & -0.216 \\
\hline $\mathrm{p}$ & $0.003^{*}$ & 0.485 & 0.066 & $0.018^{*}$ & 0.127 & $0.001^{*}$ & 0.170 \\
\hline \multicolumn{8}{|c|}{$\mathrm{VO}_{2 \max }(\mathrm{mL} / \mathrm{kg} / \mathrm{min})$} \\
\hline r & -0.441 & -0.021 & -0.287 & -0.187 & -0.337 & 0.271 & -0.512 \\
\hline $\mathrm{p}$ & $0.002^{* *}$ & 0.893 & 0.065 & 0.236 & $0.029^{*}$ & 0.082 & 0.001 \\
\hline \multicolumn{8}{|c|}{ Work (Max) } \\
\hline $\mathrm{r}$ & -0.385 & 0.017 & -0.243 & -0.312 & -0.206 & 0.467 & -0.262 \\
\hline $\mathrm{p}$ & $0.009^{*}$ & 0.913 & 0.120 & $0.044^{*}$ & 0.191 & $0.002^{*}$ & 0.093 \\
\hline \multicolumn{8}{|c|}{$\mathrm{VO}_{2}$ (peak) } \\
\hline r & -0.334 & -0.103 & -0.317 & -0.310 & -0.257 & 0.394 & -0.250 \\
\hline $\mathrm{p}$ & $0.025^{*}$ & 0.514 & $0.041^{*}$ & $0.046^{*}$ & 0.100 & $0.010^{*}$ & 0.110 \\
\hline \multicolumn{8}{|c|}{ MET (peak) } \\
\hline r & -0.431 & 0.073 & -0.132 & -0.154 & -0.282 & 0.276 & -0.369 \\
\hline $\mathrm{p}$ & $0.003^{*}$ & 0.645 & 0.406 & 0.329 & 0.070 & 0.077 & $0.016^{*}$ \\
\hline \multicolumn{8}{|c|}{ Work (peak) } \\
\hline r & -0.385 & 0.017 & -0.243 & -0.312 & -0.206 & 0.440 & -0.249 \\
\hline $\mathrm{p}$ & $0.009^{*}$ & 0.913 & 0.120 & $0.044^{*}$ & 0.191 & $0.004^{* *}$ & 0.112 \\
\hline \multicolumn{8}{|c|}{ Heart rate (peak) } \\
\hline $\mathrm{r}$ & -0.550 & 0.015 & 0.007 & -0.314 & -0.048 & 0.320 & -0.018 \\
\hline $\mathrm{p}$ & $0.000^{* *}$ & 0.927 & 0.963 & $0.043^{*}$ & 0.761 & $0.039^{*}$ & 0.908 \\
\hline \multicolumn{8}{|c|}{ RER (peak) } \\
\hline$r$ & -0.122 & -0.054 & 0.086 & 0.078 & -0.172 & 0.139 & -0.114 \\
\hline $\mathrm{p}$ & 0.426 & 0.732 & 0.586 & 0.622 & 0.277 & 0.380 & 0.471 \\
\hline \multicolumn{8}{|c|}{$\mathrm{VO}_{2}$ (vt) } \\
\hline $\mathrm{r}$ & -0.219 & -0.354 & -0.452 & -0.446 & -0.169 & 0.415 & -0.308 \\
\hline $\mathrm{p}$ & 0.180 & $0.032^{*}$ & $0.005^{* *}$ & $0.006^{* *}$ & 0.317 & $0.011^{*}$ & 0.063 \\
\hline
\end{tabular}

of six patients with AS and six healthy subjects matched for age and body size. In another pilot study in which 12 patients with AS were assessed, there was no significant reduction in exercise tolerance, ${ }^{27}$ although there was a broad range of maximum work load and $\mathrm{VO}_{2 \text { peak. In our }}$ study, the aerobic capacity was determined to be reduced compared to controls.

The low cardiorespiratory capacity observed in the group with AS is consistent with other studies comparing AS cohorts relative to control groups. The magnitude of the difference varies between $7 \%$ and $24 \%$ in the studies. This variance may be due to different patient characteristics, test protocols and $\mathrm{VO}_{2 \text { peak }}$ estimation methods. . $^{7,28,29}$ The small increases in absolute $\mathrm{VO}_{2 \text { peak }}$ are associated with lower mortality than in cardiovascular disease. ${ }^{9}$

Cardiovascular fitness decline in patients with AS is associated with mobility, muscle strength, physical function and impaired QoL. However, fitness is not associated with disease activity. ${ }^{9}$ In addition to these data, CPET was also associated with age and enthesic score; however, it was not associated with disease activity in our study.

Another cause of decreased aerobic capacity 
in patients with AS may be cardiovascular pathologies. According to the results of previous studies, conduction disorders and valvular heart disease are the most important cardiovascular findings in AS. ${ }^{30}$ Recent studies have reported the impairment of endothelial function and coronary microvascular function in patients with AS. Potential mechanisms for cardiovascular complications include a chronic inflammatory condition with increased levels of circulating cytokines and acute phase reactants. ${ }^{31,32}$ Although heart and valvular pathologies were not evaluated in our study, exercise tolerance was not associated with disease activity.

Exercise tolerance testing is the simultaneous assessment of the ability of vascular and respiratory systems to perform their functions. This is because there is a requirement for an integrated cardiopulmonary response when exercising. ${ }^{21}$ It has been stated that fatigue of the inspiratory muscles may contribute to reduced aerobic capacity in patients with AS because there is significant muscular fatigue, particularly in the diaphragm and intercostal muscles. ${ }^{33}$

Fisher et al. $^{10}$ reported on 33 patients with AS, investigating the correlation between chest expansion, pulmonary function and exercise capacity. They mentioned a significant correlation between chest expansion and vital capacity. Exercise tolerance was significantly associated with vital capacity but not with chest expansion. Vital capacity and exercise tolerance were not correlated with the duration of disease, thoracic kyphosis or ESR. In this study, it was concluded that the limitation of chest expansion in patients with AS could lead to decreased vital capacity, but it was not a significant predictive factor determining exercise tolerance. ${ }^{10}$ In our study, chest expansion was associated with both PFT and aerobic capacity.

Moreover, Hsieh et al. ${ }^{8}$ compared the aerobic capacity, pulmonary function and disease-related variables in 42 patients with AS and 42 control subjects. They reported that both aerobic capacity and PFT were lower in patients with AS. More

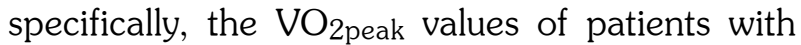
AS were $13 \%$ lower than the normal subjects. Although a significant correlation of aerobic capacity was found with vital capacity, chest expansion, Schober test, cervical range of motion, age and BASFI in patients with AS, there was no correlation between aerobic and pulmonary vital capacity with the duration of disease and disease activity. This was similar to our study and others. There was no significant statistical difference between the two groups in terms of heart rate, $\mathrm{O}_{2}$ pulse, blood pressure and RER during peak cardiovascular response. This was also similar to our study. ${ }^{8}$

Carter et al. ${ }^{7}$ assessed the CPET and aerobic capacities of 20 patients with AS and 20 healthy control patients matched for age and sex. They indicated that patients with AS showed lower $\mathrm{VO}_{2 \text { peak }}$ values than healthy controls $(25.2 \pm 1.4$ vs. $33.1 \pm 1.6 \mathrm{~mL} / \mathrm{kg} /$ minute, respectively), reporting a $24 \%$ reduction in aerobic capacity. In addition, they suggested that the ventilator threshold had decreased significantly and that there was no significant difference between the groups in terms of blood pressure response during exercise. They found that patients with AS had a lower mean working capacity (123 W-148 W) compared to controls. In this study, the respiratory and peripheral muscle functions of the participants were also assessed and the peripheral muscle function was demonstrated to be the most important determinant of aerobic capacity. In our study, patients with AS had lower ventilator thresholds and $\mathrm{VO}_{2 \text { peak }}$ values. The aerobic capacity was significantly lower in patients with AS compared to controls (116.29 watt-154.07 watt), and there was no significant difference between the blood pressure responses of the groups during exercise. The aerobic capacity was reduced by $17.6 \%$.

Carter et al. ${ }^{7}$ reported that there were no gas exchange abnormalities at resting phase or during exercise, despite impaired aerobic capacity compared to controls, in patients with AS without cardiac or pulmonary parenchymal disease. Similarly, no RER change was observed in our patient group.

A study conducted with male AS patients and controls reported that although the exercise tolerance was similar, the PFT was lower in AS patients than controls. However, patients with AS have been reported to have a higher rate of symptoms, such as exertion and dyspnea during exercise. Also, it was indicated that chest 
expansion was correlated with PFT but not with exercise tolerance..$^{15}$ In our study, chest expansion was associated with both respiratory and aerobic capacity parameters. Ozdem et al. ${ }^{34}$ found that the respiratory and aerobic capacity parameters correlated with chest expansion. Also, the clinical parameters not correlated to BASDAI and BASFI presented very similar results to our study.

The restrictive respiratory pattern was present in $22.2 \%$ of our patients with AS. Our spirometry test results are consistent with previous studies in the literature in which the restrictive pattern was reported between $18 \%$ and $52 \% .^{28,35}$

Particularly in terms of heart rate values in cardiorespiratory exercise testing, heart rate in patients with AS was significantly different compared to controls both at rest and during exercise. ${ }^{9}$ In our study, heart rate was significantly different in both rest and exercise. In addition, MET values were lower than in controls.

This study has some limitations. Firstly, the cross-sectional design precludes the determination of the causality between variables. Secondly, the sample selection used may have resulted in selection bias. And thirdly, participants who apply to the clinic of Physical Medicine and Rehabilitation may not be representative of all AS patients.

In conclusion, there was no significant difference in PFT parameters in patients with $\mathrm{AS}$, and CPET parameters were found to be significantly lower in the AS group than in the control group. This is probably due to the fact that CPET is more sensitive than PFT parameters in predicting lung, muscle and cardiac functions in patients with AS. Since $22.2 \%$ of the patients had a restrictive pattern of respiratory dysfunction, and respiratory dysfunction affects exercise tolerance, supporting patients with appropriate exercise programs is very important. This is because it is known that cardiorespiratory fitness affects the functional status and QoL positively, independently of disease activity.

\section{Declaration of conflicting interests}

The authors declared no conflicts of interest with respect to the authorship and/or publication of this article.

\section{Funding}

The authors received no financial support for the research and/or authorship of this article.

\section{REFERENCES}

1. Braun J, Sieper J. Ankylosing spondylitis. Lancet 2007;369:1379-90.

2. El Maghraoui A. Extra-articular manifestations of ankylosing spondylitis: prevalence, characteristics and therapeutic implications. Eur $\mathrm{J}$ Intern Med 2011;22:554-60.

3. Gran JT, Husby G. The epidemiology of ankylosing spondylitis. Semin Arthritis Rheum 1993;22:319-34.

4. Carbon RJ, Macey MG, McCarthy DA, Pereira FP, Perry JD, Wade AJ. The effect of 30 min cycle ergometry on ankylosing spondylitis. $\mathrm{Br} \mathrm{J}$ Rheumatol 1996;35:167-77.

5. Bulkley BH, Roberts WC. Ankylosing spondylitis and aortic regurgitation. Description of the characteristic cardiovascular lesion from study of eight necropsy patients. Circulation 1973;48:1014-27.

6. Gould BA, Turner J, Keeling DH, Hickling P, Marshall AJ. Myocardial dysfunction in ankylosing spondylitis. Ann Rheum Dis 1992;51:227-32.

7. Carter R, Riantawan P, Banham SW, Sturrock RD. An investigation of factors limiting aerobic capacity in patients with ankylosing spondylitis. Respir Med 1999;93:700-8.

8. Hsieh LF, Wei JC3, Lee HY, Chuang CC, Jiang JS, Chang KC. Aerobic capacity and its correlates in patients with ankylosing spondylitis. Int $\mathrm{J}$ Rheum Dis 2016;19:490-9.

9. O'Dwyer T, O'Shea F, Wilson F. Decreased physical activity and cardiorespiratory fitness in adults with ankylosing spondylitis: a cross-sectional controlled study. Rheumatol Int 2015;35:1863-72.

10. Fisher LR, Cawley MI, Holgate ST. Relation between chest expansion, pulmonary function, and exercise tolerance in patients with ankylosing spondylitis. Ann Rheum Dis 1990;49:921-5.

11. Feltelius N, Hedenström H, Hillerdal G, Hällgren R. Pulmonary involvement in ankylosing spondylitis. Ann Rheum Dis 1986;45:736-40.

12. Franssen MJ, van Herwaarden CL, van de Putte LB, Gribnau FW. Lung function in patients with ankylosing spondylitis. A study of the influence of disease activity and treatment with nonsteroidal antiinflammatory drugs. J Rheumatol 1986;13:936-40.

13. Heeneman S, Daemen MJ. Cardiovascular risks in spondyloarthritides. Curr Opin Rheumatol 2007; 19:358-62.

14. Seçkin U, Bölükbasi N, Gürsel G, Eröz S, Sepici V, Ekim N. Relationship between pulmonary function and exercise tolerance in patients with ankylosing spondylitis. Clin Exp Rheumatol 2000;18:503-6. 
15. Ceylan E. Cardiopulmonary exercise testing. J Clin Exp Invest 2014;5:504-9.

16. Hawker GA, Mian S, Kendzerska T, French M. Measures of adult pain: Visual Analog Scale for Pain (VAS Pain), Numeric Rating Scale for Pain (NRS Pain), McGill Pain Questionnaire (MPQ), Short-Form McGill Pain Questionnaire (SF-MPQ), Chronic Pain Grade Scale (CPGS), Short Form-36 Bodily Pain Scale (SF-36 BPS), and Measure of Intermittent and Constant Osteoarthritis Pain (ICOAP). Arthritis Care Res (Hoboken) 2011;63:240-52.

17. Garrett S, Jenkinson T, Kennedy LG, Whitelock H, Gaisford P, Calin A. A new approach to defining disease status in ankylosing spondylitis: the Bath Ankylosing Spondylitis Disease Activity Index. J Rheumatol 1994;21:2286-91.

18. Calin A, Garrett S, Whitelock H, Kennedy LG, O'Hea J, Mallorie P, et al. A new approach to defining functional ability in ankylosing spondylitis: the development of the Bath Ankylosing Spondylitis Functional Index. J Rheumatol 1994;21:2281-5.

19. Jenkinson TR, Mallorie PA, Whitelock HC, Kennedy LG, Garrett SL, Calin A. Defining spinal mobility in ankylosing spondylitis (AS). The Bath AS Metrology Index. J Rheumatol 1994;21:1694-8.

20. Hidding A, van der Linden S, de Witte L. Therapeutic effects of individual physical therapy in ankylosing spondylitis related to duration of disease. Clin Rheumatol 1993;12:334-40.

21. Wasserman K, Hansen JE, Sue DY, Stringer WW, Sietsema KE, Sun XG, et al. Principles of Exercise Testing and Interpretation: Including Pathophysiology and Clinical Applications. 5th ed. Philadelphia: Lippincott Williams \& Wilkins; 2005

22. Doward LC, Spoorenberg A, Cook SA, Whalley D, Helliwell PS, Kay LJ, et al. Development of the ASQoL: a quality of life instrument specific to ankylosing spondylitis. Ann Rheum Dis 2003;62:20-6.

23. Heuft-Dorenbosch L, Spoorenberg A, van Tubergen A, Landewé $\mathrm{R}$, van ver Tempel $\mathrm{H}$, Mielants $\mathrm{H}$, et al. Assessment of enthesitis in ankylosing spondylitis. Ann Rheum Dis 2003;62:127-32.

24. Miller MR, Hankinson J, Brusasco V, Burgos F, Casaburi R, Coates A, et al. Standardisation of spirometry. Eur Respir J 2005;26:319-38.
25. American Thoracic Society; American College of Chest Physicians. ATS/ACCP Statement on cardiopulmonary exercise testing. Am J Respir Crit Care Med 2003;167:211-77.

26. Elliott CG, Hill TR, Adams TE, Crapo RO, Nietrzeba RM, Gardner RM. Exercise performance of subjects with ankylosing spondylitis and limited chest expansion. Bull Eur Physiopathol Respir 1985;21:363-8.

27. van der Esch $M$, van 't Hul AJ, Heijmans $M$, Dekker J. Respiratory muscle performance as a possible determinant of exercise capacity in patients with ankylosing spondylitis. Aust $\mathrm{J}$ Physiother 2004;50:41-5.

28. Sampaio-Barros PD, Cerqueira EM, Rezende SM, Maeda L, Conde RA, Zanardi VA, et al. Pulmonary involvement in ankylosing spondylitis. Clin Rheumatol 2007;26:225-30.

29. Halvorsen S, Vøllestad NK, Fongen C, Provan SA, Semb AG, Hagen KB, et al. Physical fitness in patients with ankylosing spondylitis: comparison with population controls. Phys Ther 2012;92:298-309.

30. Roldan CA. Valvular and coronary heart disease in systemic inflammatory diseases: Systemic Disorders in heart disease. Heart 2008;94:1089-101.

31. American College of Sports Medicine. In: Thompson WR, Gordon NF, Pescatello LS, editors. ACSM's Guidelines for Exercise Testing and Prescription. Philadelphia: Lippincott Williams \& Wilkins; 2010

32. Pieringer $H$. Impaired endothelial function in patients with ankylosing spondylitis. Rheumatology (Oxford) 2006;45:1319.

33. Grassino A, Gross D, Macklem PT, Roussos C, Zagelbaum G. Inspiratory muscle fatigue as a factor limiting exercise. Bull Eur Physiopathol Respir 1979;15:105-15.

34. Ozdem Yr O, Inanici F, Hasçelik Z. Reduced vital capacity leads to exercise intolerance in patients with ankylosing spondylitis. Eur J Phys Rehabil Med 2011;47:391-7.

35. Berdal G, Halvorsen S, van der Heijde D, Mowe M, Dagfinrud H. Restrictive pulmonary function is more prevalent in patients with ankylosing spondylitis than in matched population controls and is associated with impaired spinal mobility: a comparative study. Arthritis Res Ther 2012;14:19. 